\title{
Nonoperative Antibiotic Treatment of Appendicitis in Adults: A Survey among Clinically Active Surgeons
}

\author{
Alexander Reinisch ${ }^{a} \quad$ Martin Reichert $^{\mathrm{b}} \quad$ Andreas Hecker $^{\mathrm{b}} \quad$ Winfried Padberg $^{\mathrm{b}}$ \\ Frank Ulrich $^{a}$ Juliane Liese ${ }^{b}$ \\ a Department of General, Visceral and Oncologic Surgery, Hospital and Clinics Wetzlar, Wetzlar, Germany; \\ ${ }^{b}$ Department of General, Visceral, Thoracic, Transplant and Pediatric Surgery, University Hospital of Giessen, \\ Giessen, Germany
}

\section{Keywords}

Appendicitis · Antibiotics · Nonoperative treatment

\begin{abstract}
Background: As a result of well-publicized studies, the nonsurgical antibiotic therapy of uncomplicated acute appendicitis has been propagated since 2006. A final assessment regarding efficiency and long-term results is not possible; however, nonoperative therapy of acute appendicitis is actually being discussed more diversely and receives a lot of attention. It is still unknown how far this therapy has found its way into everyday clinical care. Methods: An online questionnaire was sent to 1,400 randomly selected specialists for general/visceral surgery in Germany. Representativeness was achieved by a preselection according to the geographical origin and the care level of the hospitals. Results: $14 \%$ of surgeons stated that they methodically treat appendicitis conservatively. $38.1 \%$ do so in exceptional cases, while $48.8 \%$ reject this therapy. For methodically use, sonography or computed tomography is demanded beforehand. Nonoperative therapy is performed more often in metropolitan areas and maximum-care/university hospitals. Patients' request for antibiotic therapy is an important factor for conservative treatment. The main argument against this therapy is "medical doubts." $26 \%$ of the surgeons would treat their own appendicitis conservatively. There are distinct associations between the application of conservative therapy, satisfac-
\end{abstract}

tion with it, and expectations about future development. The response rate was $19.9 \%$. Conclusion: The nonoperative antibiotic therapy of appendicitis is part of clinical practice in Germany. There are differences in preconditions as well as in the acceptance of this therapeutic option with a high proportion of general rejection.

(c) 2020 S. Karger AG, Basel

\section{Introduction}

In 1956, the surgeon Eric Coldrey presented a concept for the antibiotic therapy of acute appendicitis $[1,2]$. This was reactivated following series of randomized clinical trials after 2006. In these studies, the safety of the nonoperative treatment was demonstrated, while other results were inconsistent [3-8]. At times, antibiotic therapy for appendicitis was advocated so enthusiastically that a general change of the surgical practice was discussed [9].

These studies triggered a discussion in the scientific community $[10,11]$. Although a definite assessment is currently difficult, nonoperative therapy of acute appendicitis is actually being discussed more diversely. Nevertheless, current guidelines still refer to surgery as the gold standard [12].

It remains unclear to what extent antibiotic therapy of acute appendicitis is used in clinical practice. An US American analysis showed an increase in antibiotics-treated ap- 
Table 1. Demography

\begin{tabular}{|c|c|c|c|c|c|c|c|c|}
\hline & & \multicolumn{2}{|c|}{$\begin{array}{l}\text { Methodically } \\
\text { nonoperative antibiotic } \\
\text { treatment }\end{array}$} & \multicolumn{2}{|c|}{$\begin{array}{l}\text { Nonoperative } \\
\text { antibiotic treatment in } \\
\text { exceptional cases }\end{array}$} & \multicolumn{2}{|c|}{$\begin{array}{l}\text { Rejection of } \\
\text { nonoperative antibiotic } \\
\text { treatment }\end{array}$} & \multirow[t]{2}{*}{$p$} \\
\hline & & $n$ & $\%$ & $n$ & $\%$ & $n$ & $\%$ & \\
\hline Total & & 39 & 14 & 106 & 38.1 & 133 & 48.8 & \\
\hline Gender & $\begin{array}{l}\text { female } \\
\text { male }\end{array}$ & $\begin{array}{r}4 \\
35\end{array}$ & $\begin{array}{l}10.3 \\
89.7\end{array}$ & $\begin{array}{l}30 \\
76\end{array}$ & $\begin{array}{l}28.3 \\
71.7\end{array}$ & $\begin{array}{l}37 \\
96\end{array}$ & $\begin{array}{l}27.8 \\
72.2\end{array}$ & $\begin{array}{l}\text { ns } \\
0.017^{\mathrm{a}}\end{array}$ \\
\hline Hospital level & $\begin{array}{l}\text { I, II } \\
\text { III }\end{array}$ & $\begin{array}{l}24 \\
15 \\
\end{array}$ & $\begin{array}{l}61.5 \\
38.5\end{array}$ & $\begin{array}{l}74 \\
32 \\
\end{array}$ & $\begin{array}{l}69.8 \\
30.2 \\
\end{array}$ & $\begin{array}{r}107 \\
26 \\
\end{array}$ & $\begin{array}{l}80.5 \\
19.6\end{array}$ & $\begin{array}{l}0.02^{\mathrm{c}} \\
\mathrm{ns}\end{array}$ \\
\hline Consultant for & $\begin{array}{l}<5 \text { years } \\
6-10 \text { years } \\
>10 \text { years }\end{array}$ & $\begin{array}{r}4 \\
9 \\
26\end{array}$ & $\begin{array}{l}10.3 \\
23.08 \\
66.67\end{array}$ & $\begin{array}{l}25 \\
28 \\
51\end{array}$ & $\begin{array}{l}23.6 \\
26.4 \\
48.1\end{array}$ & $\begin{array}{l}29 \\
33 \\
62\end{array}$ & $\begin{array}{l}21.8 \\
24.8 \\
46.6\end{array}$ & $\begin{array}{l}\text { ns } \\
\text { ns } \\
\text { ns }\end{array}$ \\
\hline Federal state & MET & 5 & 12.8 & 14 & 13.2 & 4 & 3 & $\begin{array}{l}0.025^{b} \\
0.002^{\mathrm{c}}\end{array}$ \\
\hline $\begin{array}{l}\text { Population } \\
\text { density }\end{array}$ & $\begin{array}{l}\text { dense } \\
\text { sparse }\end{array}$ & $\begin{array}{l}12 \\
22\end{array}$ & $\begin{array}{l}30.8 \\
56.4\end{array}$ & $\begin{array}{l}32 \\
60\end{array}$ & $\begin{array}{l}30.2 \\
56.6\end{array}$ & $\begin{array}{l}55 \\
74\end{array}$ & $\begin{array}{l}41.4 \\
55.6\end{array}$ & $\begin{array}{l}\mathrm{ns} \\
\mathrm{ns}\end{array}$ \\
\hline
\end{tabular}

MET, the 5 largest metropolitan regions; ns, no significant differences. ${ }^{a}$ Methodically nonoperative antibiotic treatment. ${ }^{b}$ Nonoperative antibiotic treatment in exceptional cases. ${ }^{c}$ Rejection of nonoperative antibiotic treatment.

pendicitis by 2011, while data from an US survey address this therapy only as a subordinate target $[13,14]$. Beyond this, any data is lacking. Moreover, we have no information on the criteria that influence the choice of this therapy.

The aims of this study were to gain an overview of the use of antibiotic therapy for appendicitis in adults in everyday German hospital life.

\section{Methods}

The study was approved by the Institutional Review Board (AZ 204/18) and registered in the German Clinical Trials Register (DRKS00015887). One recruitment e-mail was sent to board-certified consultants for general and/or visceral surgery in German hospitals.

Out of 1,156 surgical clinics, those clinics which published the e-mail addresses of the medical staff openly were selected. These addresses were added to lists and differentiated per federal state. From each list, 80 surgeons from first- and second-level hospitals (level I and II [community/general/regional hospitals]) and 20 surgeons from third-level hospitals (level III [central/University hospitals]) were randomly selected using the Microsoft Excel ${ }^{\circledR}$ function RANDBETWEEN $(\mathrm{X} ; \mathrm{Y})$ [15]. The list of surgeons from "Bremen" was incorporated into "Lower Saxonia." Another $80+20$ surgeons were accordingly selected from hospitals in Germany's 5 largest metropolitan areas (MET): Berlin, Munich, Hamburg, Cologne, and Frankfurt. Surgeons from federal states with a high population density $\left(>220\right.$ persons $\left./ \mathrm{km}^{2}\right)$ were compared to those from states with a low population density.

The e-mail included general study information and a link to the survey (online Supplement 1; for all online suppl. material, see www.karger.com/doi/10.1159/000506058). It was clarified that only uncomplicated (not gangrenous/not perforated) appendicitis was the subject of this study. The survey was conducted in German. Incorrect or failed deliveries were replaced by newly selected addressees.

In addition to the answers, we recorded federal state/MET, hospital level (level I and II vs. III), time since board certification, and gender. The questionnaire included different question sequences (online Supplement 2). Questionnaire respondent traceability was technically impossible. The questionnaire was active for 30 working days.

A $\chi^{2}$ test was used to compare nominally scaled parameters, and a Mann-Whitney U test (2 groups) or Kruskal-Wallis H test ( $>2$ groups) was used to compare ordinally scaled parameters. A $p$ value of $<0.05$ was considered statistically significant.

\section{Results}

\section{Response}

Out of 1,400 questionnaires, 278 (19.9\%) were completed. The response rate was significantly higher for surgeons of level III than for surgeons of level I and II hospitals (26.1 vs. $18.7 \%, p=0.024)$.

\section{Antibiotic Therapy of Acute Appendicitis}

When asked whether they treat uncomplicated appendicitis with antibiotics, 39 (14\%) surgeons stated "yes" and 133 (48.8\%) stated "no"; another 106 (38.1\%) stated that they use antibiotic treatment "in exceptional cases." Partially significant differences between these groups of surgeons were noted (Table 1; see section Comparative Presentation). 


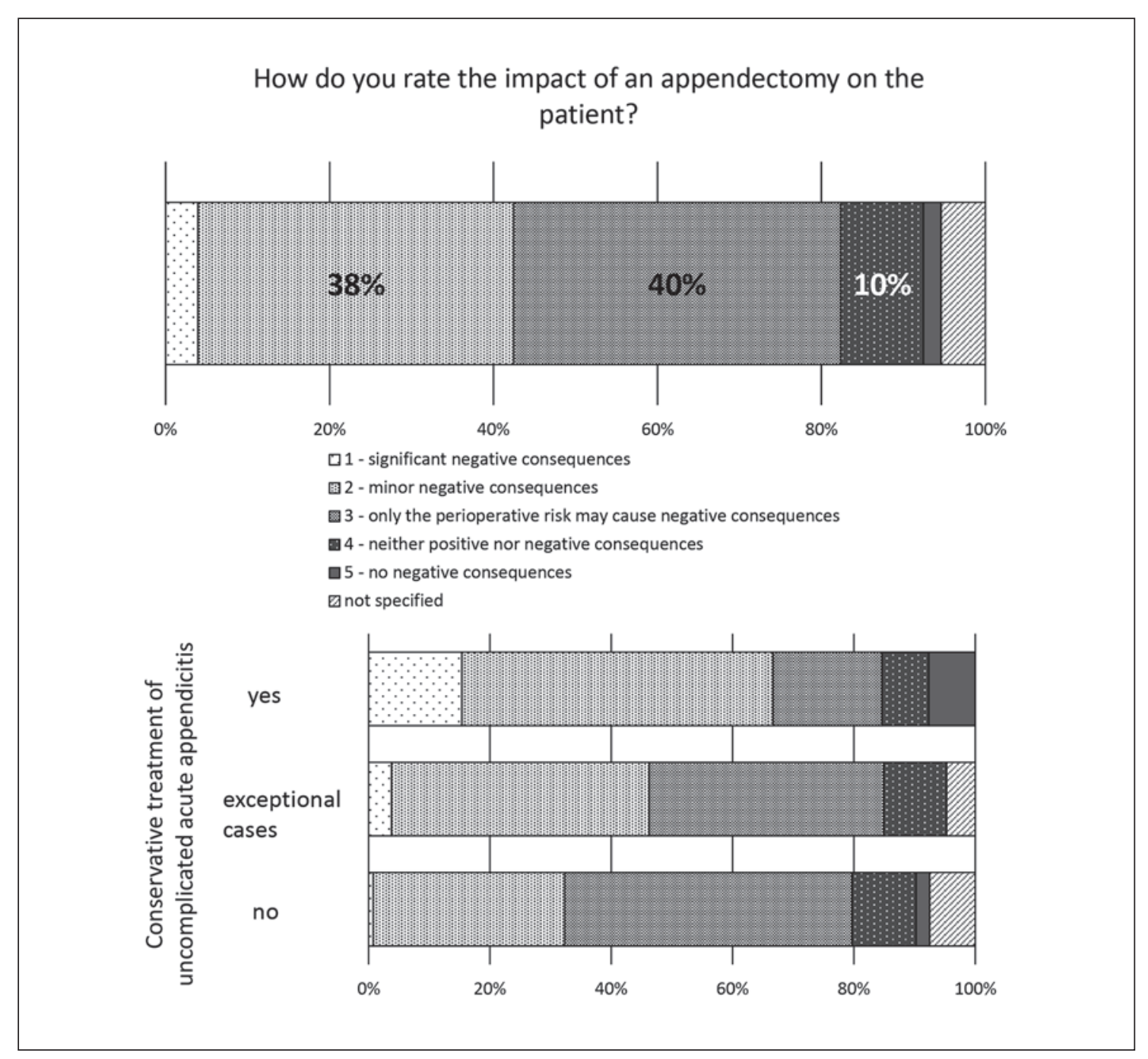

Fig. 1. Impact of appendectomy on the patient.

Methodical Antibiotic Nonoperative Therapy

Of the surgeons who methodically treat uncomplicated acute appendicitis nonoperatively, $61.5 \%(n=24)$ treated $1-10 \%, 23.1 \%(n=9)$ treated $11-20 \%, 10.3 \%(n=$ 4) treated $21-30 \%$, and $5.1 \%(n=2)$ treated up to $40 \%$ of the patients nonoperatively. On average, surgeons in this group treated 3 patients per annum. $43.6 \%$ of the surgeons only reported the proportion of patients.

At least one imaging procedure, sonography or computed tomography (CT)/magnetic resonance imaging (MRI), was mandatory for all surgeons; $84.6 \%$ requested sonography, $56.4 \%$ requested CT/MRI, and $41 \%$ both. 92.3\% demanded (among other parameters) leukocyte counts and C-reactive protein. The combination of at least one imaging result with leucocyte count and C-reactive protein as well as the overall clinical impression was mandatory for $89.7 \%$ of surgeons. Temperature (38.5\%) and interleukin 6/procalcitonin (5.3\%) were requested less frequently.
The question regarding the most decisive factor for the consideration of a conservative therapy was answered by all surgeons. In $46.2 \%$, the combination of surgeon's recommendation and patient's demand led to nonoperative therapy. In $30.8 \%$ the surgeon's recommendation and in $23.1 \%$ the patient's request was decisive.

$79.5 \%$ of the surgeons were rather satisfied or satisfied with the results of antibiotic nonoperative treatment, and none was rather unsatisfied or unsatisfied; $20.5 \%$ did not make an assessment.

\section{Antibiotic Nonoperative Therapy in Exceptional Cases}

A total of 106 surgeons stated that they treat acute appendicitis nonoperatively in exceptional cases. The main reason for an exceptional antibiotic therapy was the explicit and active request of the patient (40.9\%). Special clinical circumstances (19.1\%), usually very mild clinical symptoms and/or a low inflammatory activity, was the second most 


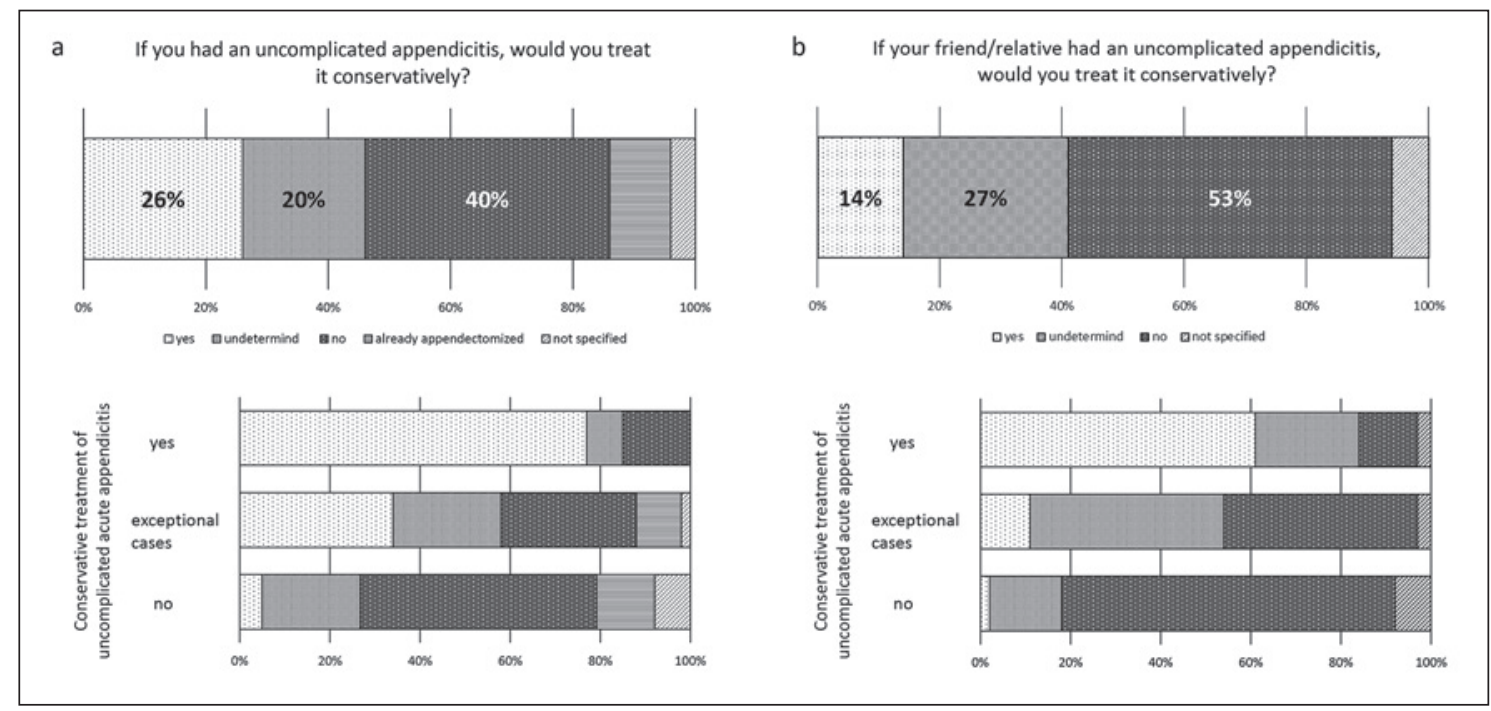

Fig. 2. a, b Hypothetical treatment of appendicitis.

frequently stated reason, and $18.2 \%$ stated an exceptionally high perioperative risk as the reason for a conservative therapy. In $19.1 \%$, the combination of the patient's request and high perioperative risk led to such a therapy.

$97.2 \%$ explained why they do not methodically treat appendicitis conservatively. 51\% reported medical doubts about this therapy. Legal concerns were ranked second with ambiguous scientific evidence (each 39\%), and 14\% stated that they had too few suitable patients. A total of $11.3 \%$ were concerned about accounting.

$60.9 \%$ of MET hospital surgeons offered nonoperative treatment in exceptional cases; this proportion is significantly higher than that of other regions (total $36.8 \%, p=$ $0.024)$.

\section{Rejection of Antibiotic Nonoperative Therapy}

A total of 133 surgeons stated that they never treat uncomplicated acute appendicitis conservatively. The main reason for rejection was medical doubt (68\%). Ambiguous scientific evidence and concerns about legal consequences were named by $39 \% ; 18 \%$ stated that this treatment option is generally rejected by their clinic. Uncertainties regarding accounting were stated by $10 \%$.

Significantly more level I and II surgeons than level III surgeons rejected this therapy ( 80.6 vs. $19.6 \%, p=0.02$ ).

\section{Comparative Presentation}

Differences between the surgeons who regularly/methodically, in exceptional cases, or not at all treated appendicitis nonoperatively were analyzed (Table 1).

\section{Demography}

The proportion of male surgeons who methodically treated appendicitis nonoperatively was significantly higher than that of female surgeons (Table 1; 16.9 vs. $5.6 \%, p=0.017)$. Distribution according to the period of board certification did not differ significantly.

In relation to all groups (methodical conservative treatment, conservative treatment in exceptional cases, rejection of conservative therapy), more level III hospital surgeons methodically treated appendicitis nonoperatively compared to level I and II surgeons, but this difference did not reach significance (20.6 vs. $11.7 \%, p=0.076$ ). Significantly more level I and II hospital surgeons rejected antibiotic treatment ( 52.2 vs. $35.6 \%, p=0.02$ ). Significantly more surgeons from MET treated appendicitis methodically or in exceptional cases conservatively compared to those not from MET ( 82.6 vs. $52.2 \%, p=0.002$ ).

\section{Assumed Consequences of Appendectomy}

Surgeons who treat appendicitis methodically nonoperatively consider the consequences of appendectomy to be significantly more severe than those who treat conservatively only in exceptional cases or never (Fig. 1; 5 - no negative consequences vs. 1 - significant negative consequences, methodically: $2.41 \pm 1.09$ vs. exceptional cases: $2.58 \pm 0.574$ vs. never: $2.8 \pm 0.743, p<0.001)$. Surgeons working in MET assess the effects of an appendectomy to be significantly graver for the patient (MET vs. rest, 2.48 \pm 0.898 vs. $2.68 \pm 0.803, p=0.001$ ).

\section{Therapy of Appendicitis in Oneself and Related}

Persons

Surgeons were questioned on nonoperative treatment for hypothetical appendicitis in themselves or a friend/ relative as an indirect parameter for the attitude towards this therapy. $26 \%$ selected antibiotic therapy for themselves, $40 \%$ rejected the nonoperative therapy, $20 \%$ were 


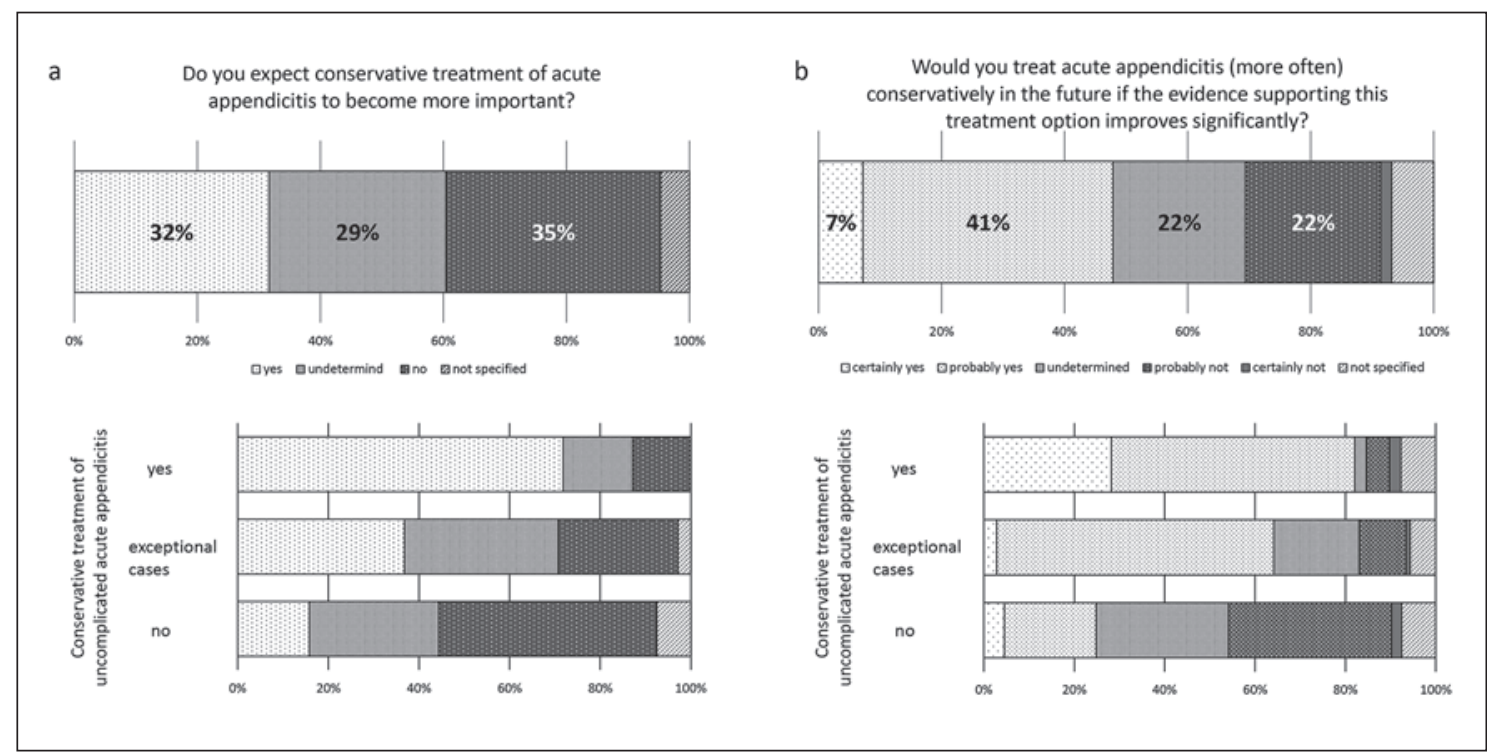

Fig. 3. a Expectations of future importance. b Expectations of future application.

undecided, and 10\% were appendectomized. Proportions of surgeons who would treat the hypothetical appendicitis of a friend/relative nonoperatively differ slightly (Fig. 2a, b).

Conservative treatment of themselves and relatives is chosen significantly more often by surgeons who apply this form of therapy (methodically vs. exceptional cases vs. never, $p<0.0001$; exceptional cases vs. never, $p<0.0001$ ). If a surgeon did not perform a conservative therapy, she/ he rejected this treatment significantly more often for herself/himself or relatives ( $p=0.0002$ and $p=0.025)$.

Surgeons with 6-10 years of experience $(p=0.14)$, from level III hospitals $(p=0.013)$, and female surgeons $(p=0.026)$ would use antibiotic treatment on themselves at a significantly higher rate. General rejection was found more often in level I and II hospital surgeons (64.1 vs. $43.5 \%, p=0.004$ ).

Surgeons who would treat appendicitis in themselves conservatively considered the consequences of appendectomy to be significantly more serious than those who would not treat themselves nonoperatively $(2.31 \pm 0.383$ vs. $2.81 \pm 0.803, p<0.0001)$.

Expectations about Future Trends

$35 \%$ of surgeons do not expect antibiotic treatment to become more important in the future. $32 \%$ expect an increase in importance, i.e., more often, surgeons actually using this therapy $(71.8 \%, p<0.0002)$ and those from $\operatorname{MET}(p=0.001)$ (Fig. 3a).

Surgeons who routinely use antibiotic appendicitis therapy state that they will use this therapy more often if the evidence improves (Fig. 3b) compared to those who currently reject this therapy or use it in exceptional cases
( $4.11 \pm 0.894$ vs. $3.57 \pm 0.785$ vs. $2.88 \pm 0.946, p<0.0001)$. Surgeons from MET (3.74 \pm 0.689 vs. $3.29 \pm 1.001, p=$ $0.027)$ as well as those from level III hospitals (3.58 \pm 0.881 vs. $3.23 \pm 1.006, p=0.008$ ) state that they would perform this therapy more frequently given improved evidence.

\section{Discussion/Conclusion}

After more than 100 years of successful surgical therapy of acute appendicitis, nonoperative antibiotic therapy is increasingly discussed and also applied [11]. However, little is known about nonoperative therapy for uncomplicated appendicitis in everyday clinical practice [14]. Our study provides valuable information on this topic by using an approved examining technique: a survey among clinically active surgeons. The response rate of $19.9 \%$ was comparable to other surveys in surgery [16].

In our study, antibiotic nonoperative treatment of uncomplicated appendicitis is remarkably well accepted among the surveyed surgeons. By summing up those surgeons who methodically or exceptionally treat appendicitis conservatively, more than $50 \%$ of the surgeons use this therapeutic option. This differs clearly from the reported rate of $15 \%$ in the USA by Yeh et al. [14].

The rate of surgeons that are rather satisfied or satisfied with the antibiotic therapy is high (79.5\%); none are dissatisfied. This is notable, especially against the background of reported recurrence rates of $39 \%$ within 5 years, which cannot be regarded as very satisfactory [17].

For all that, it remains interesting that even the surgeons who regularly use antibiotic treatment treat only 
one small subgroup of their patients nonoperatively; $84.6 \%$ treated under $20 \%$ of their patients conservatively. This is consistent with the largest study by Salminen et al. [5] in which only $5.8 \%$ of the 4,380 appendicitis patients were treated with antibiotics.

Our data provide a clear indication that this form of therapy is quite applicable in Germany and that its users are satisfied. It remains unclear what triggers this satisfaction.

For the first time, data on decision-making on nonoperative therapy are available. Surgeons who methodically treat nonoperatively often decide on this therapy together with their patients. In approximately half of the cases, the decision on nonoperative therapy is made jointly by the patient and the surgeon. In less than onethird of the cases, the surgeon's recommendation is crucial.

Surgeons who treated appendicitis in exceptional cases nonoperatively were asked for their "exception criteria." The main motivation named was the explicit and active patient request (40\%), followed by rather low level of inflammatory activity (19.1\%) or patient-related high risk $(18.2 \%)$. This indicates that the patient is widely involved in the choice of treatment.

After all, the largest group of surgeons in this survey never uses nonoperative antibiotic treatment of appendicitis (48.8\%). In this group, as among those who treat nonoperatively only in exceptional cases, we asked for the reasons for the critical attitude. The main reason were medical doubts (general refusal 68\%, exceptional cases $51 \%$ ). This is reasonable in the light of the current studies and meta-analyses that show relevant therapy failure and recurrence rates [18-20]. Insufficient scientific evidence (general refusal 40\%, exceptional cases $39 \%)$ is named in second place together with medicolegal concerns [19]. A clear legal assessment of this therapy is currently impossible. In Germany, by now the medico-legal risks of omitted surgery for appendicitis are emphasized [21, 22].

Of particular interest are our findings which reflect the surgeons' attitude towards antibiotic therapy of uncomplicated acute appendicitis. Surgeons who regularly treat appendicitis conservatively consider the consequences of an appendectomy as graver than those who do not. Some studies show an increased complication rate in appendectomized compared to antibiotics-treated patients; however, long-term adverse consequences of appendectomy are unclear $[23,24]$.

We asked the surgeons how they would treat themselves or their relatives. The results correlate with the application of antibiotic therapy for appendicitis. The proportion of surgeons who answered "yes" for self-treatment was even higher than the proportion of those who practice this form of therapy.

Survey on Nonoperative Treatment of Appendicitis
Looking at the subgroups of surgeons who regularly/ exceptionally/never use nonoperative therapy shifts the ratios distinctly. Only 5\% of surgeons who reject antibiotic therapy in professional life would treat their own appendicitis conservatively, while $61 \%$ of those who perform this therapy would use it for themselves. These results are in contrast to findings in a general population survey in which $9.4 \%$ of respondents wanted antibiotic treatment for themselves [25].

Finally, we asked about expectations about the future. One-third expect this therapy to become more important, one-third does not. Again, there are significant differences between surgeons using antibiotic therapy and those who do not or only in exceptional cases. Interestingly, approximately half of the surgeons say that they would use this therapy more often, if the evidence for antibiotic therapy improved. It is unclear what prompted this positive attitude, since actual data provides only limited cause for positive expectations $[17,26]$. Among the surgeons who never use nonoperative antibiotic therapy, the attitude on this therapy is comparatively critical, even with improved evidence. Our study indicated that surgeons working in level III or MET hospitals are more positive about nonoperative therapy of uncomplicated appendicitis. The data collected and the current literature do not provide a conclusive explanation for this observation. Further studies, such as focused interviews with surgeons, may help to understand what causes the different attitudes to this therapy.

There are some limitations to this study. The response rate was relatively low. However, this is an effect of the broad and only specifically preselected survey. Comparable studies which surveyed only members of a professional society achieved higher response rates, but this is associated with a relevant selection bias [14].

Although questions were formulated to minimize response bias, the effects of question order bias and especially social desirability bias cannot be completely ruled out [27]. The survey reflects the situation in Germany. The health system in Germany gives the surgeon extensive freedom in decisions about therapeutic procedures, so, these German results are of explicit interest. However, it would be important to study this topic in other countries as well.

This is the first overview of the use of antibiotic therapy for acute appendicitis in clinical practice. It was possible to gather information about factors that influence surgeons' decisions and describe their general attitude. Antibiotic nonsurgical treatment of acute appendicitis is part of clinical practice; however, we could not notice a general change in surgical practice as assumed by some authors [9]. However, the study shows that the surveyed surgeons are deeply divided in terms of the application but also the assessment of this form of therapy. 


\section{Statement of Ethics}

The published research complies with the guidelines for human studies and was conducted ethically in accordance with the World Medical Association Declaration of Helsinki. The study was approved by the Review Board of the Justus Liebig University Giessen (AZ 204/18) and registered in the German Clinical Trials Register (DRKS00015887).

\section{Disclosure Statement}

The authors have no conflicts of interest to declare.

\section{Funding Sources}

No funding or sponsoring was obtained.

\section{Author Contributions}

Study conception and design: A. Reinisch, J. Liese. Drafting of the manuscript: A. Reinisch, J. Liese. Acquisition of data: A. Reinisch, M. Reichert. Analysis and interpretation of data: A. Reinisch, M. Reichert, A. Hecker, J. Liese. Critical revision of the manuscript: J. Liese, F. Ulrich, W. Padberg. Final approval of the version to be submitted: all authors.

\section{References}

1 Coldrey E. Treatment of acute appendicitis. BMJ. 1956 Dec;2(5007):1458-61.

2 Coldrey E. Five years of conservative treatment of acute appendicitis. J Int Coll Surg. 1959;32:255-61.

3 Di Saverio S, Sibilio A, Giorgini E, Biscardi A, Villani S, Coccolini F, et al. The NOTA Study (Non Operative Treatment for Acute Appendicitis): prospective study on the efficacy and safety of antibiotics (amoxicillin and clavulanic acid) for treating patients with right lower quadrant abdominal pain and long-term follow-up of conservatively treated suspected appendicitis. Ann Surg. 2014 Jul;260(1):10917.

4 Vons C, Barry C, Maitre S, Pautrat K, Leconte $\mathrm{M}$, Costaglioli B, et al. Amoxicillin plus clavulanic acid versus appendicectomy for treatment of acute uncomplicated appendicitis: an open-label, non-inferiority, randomised controlled trial. Lancet. 2011 May;377(9777): 1573-9.

5 Salminen P, Paajanen H, Rautio T, Nordström P, Aarnio M, Rantanen T, et al. Antibiotic Therapy vs Appendectomy for Treatment of Uncomplicated Acute Appendicitis: The APPAC Randomized Clinical Trial. JAMA. 2015 Jun;313(23):2340-8.

6 Styrud J, Eriksson S, Nilsson I, Ahlberg G, Haapaniemi S, Neovius G, et al. Appendectomy versus antibiotic treatment in acute appendicitis. a prospective multicenter randomized controlled trial. World J Surg. 2006 Jun; 30(6):1033-7.

7 Hansson J, Körner U, Khorram-Manesh A, Solberg A, Lundholm K. Randomized clinical trial of antibiotic therapy versus appendicectomy as primary treatment of acute appendicitis in unselected patients. Br J Surg. 2009 May;96(5):473-81.

8 Turhan AN, Kapan S, Kütükçü E, Yiğitbaş H, Hatipoğlu S, Aygün E. Comparison of operative and non operative management of acute appendicitis. Ulus Travma Acil Cerrahi Derg. 2009 Sep;15(5):459-62.
9 Hansson J, Körner U, Ludwigs K, Johnsson E, Jönsson C, Lundholm K. Antibiotics as firstline therapy for acute appendicitis: evidence for a change in clinical practice. World J Surg. 2012 Sep;36(9):2028-36.

10 Flum DR. Clinical practice. Acute appendicitis-appendectomy or the "antibiotics first" strategy. N Engl J Med. 2015 May;372(20): 1937-43.

11 McBurney C. Experiences with early operative interference in cases of disease of the vermiform appendix. N Y Med J. 1889;50:676-84.

12 Gorter RR, Eker HH, Gorter-Stam MA, Abis GS, Acharya A, Ankersmit M, et al. Diagnosis and management of acute appendicitis. EAES consensus development conference 2015. Surg Endosc. 2016 Nov;30(11):4668-90.

13 Khalil M, Rhee P, Jokar TO, Kulvatunyou N, O'Keeffe T, Tang A, et al. Antibiotics for appendicitis! Not so fast. J Trauma Acute Care Surg. 2016 Jun;80(6):923-32.

14 Yeh DD, Sakran JV, Rattan R, Mehta A, Ruiz $\mathrm{G}$, Lieberman $\mathrm{H}$, et al. A survey of the practice and attitudes of surgeons regarding the treatment of appendicitis. Am J Surg. 2019 Jul; 218(1):106-112.

15 McCord C, Ozgediz D, Beard J. General surgical emergencies. In: Debas HT, Donkor P, Gawande A, editors. Essential Surgery: Disease Control Priorities. 3rd ed. Vol 1. Washington (DC): The International Bank for Reconstruction and Development/The World Bank; 2015.

16 Faivre G, Marillier G, Nallet J, Nezelof S, Clment I, Obert L. Are French orthopedic and trauma surgeons affected by burnout? Results of a nationwide survey. Orthop Traumatol Surg Res. 2019 Apr;105(2):395-9.

17 Salminen P, Tuominen R, Paajanen H, Rautio T, Nordström P, Aarnio M, et al. Five-Year Follow-up of Antibiotic Therapy for Uncomplicated Acute Appendicitis in the APPAC Randomized Clinical Trial. JAMA. 2018 Sep; 320(12):1259-65.

18 Podda M, Gerardi C, Cillara N, Fearnhead N, Gomes CA, Birindelli A, et al. Antibiotic Treatment and Appendectomy for Uncomplicated Acute Appendicitis in Adults and Children: A Systematic Review and Meta-analysis. Ann Surg. 2019 Dec;270(6):1028-40.
19 Poprom N, Numthavaj P, Wilasrusmee C, Rattanasiri S, Attia J, McEvoy M, et al. The efficacy of antibiotic treatment versus surgical treatment of uncomplicated acute appendicitis: systematic review and network meta-analysis of randomized controlled trial. Am J Surg. 2019 Jul;218(1):192-200.

20 Poon SH, Lee JW, Ng KM, Chiu GW, Wong BY, Foo CC, et al. The current management of acute uncomplicated appendicitis: should there be a change in paradigm? A systematic review of the literatures and analysis of treatment performance. World J Emerg Surg. 2017 Oct;12(1):46.

21 Vinz H, von Bülow M, Neu J. [Delayed appendectomy because of diagnostic malpractice: Experiences of the Arbitration Board of the North German Medical Associations]. Z Evid Fortbild Qual Gesundhwes. 2015;109(910):704-13.

22 Glatz U. [Uncomplicated appendicitis: is surgery always necessary?]. Dtsch Med Wochenschr. 2014 Aug;139(34-35):1697.

23 Antibiotic therapy for acute appendicitis in adults. Fewer immediate complications than with surgery, but more subsequent failures. Prescrire Int. 2014 Jun;23(150):158-60.

24 Rasmussen T, Fonnes S, Rosenberg J. LongTerm Complications of Appendectomy: A Systematic Review. Scand J Surg. 2018 Sep; 107(3):189-96

25 Hanson AL, Crosby RD, Basson MD. Patient Preferences for Surgery or Antibiotics for the Treatment of Acute Appendicitis. JAMA Surg. 2018 May;153(5):471-8.

26 Ceresoli M, Pisano M, Allievi N, Poiasina E, Coccolini F, Montori G, et al. Never put equipoise in appendix! Final results of ASAA (antibiotics vs. surgery for uncomplicated acute appendicitis in adults) randomized controlled trial. Updates Surg. 2019 Jul;71(2):381-387.

27 Furnham A. Response bias, social desirability and dissimulation. Pers Individ Dif. 1986; 7(3):385-400. 